\title{
Long-Distance Axonal Regeneration in the Transected Adult Rat Spinal Cord Is Promoted by Olfactory Ensheathing Glia Transplants
}

\author{
Almudena Ramón-Cueto,, ${ }^{1,2}$ Giles W. Plant, ${ }^{1}$ Jesus Avila, ${ }^{2}$ Mary Bartlett Bunge ${ }^{1,3}$ \\ ${ }^{1}$ The Chambers Family Electron Microscopy Laboratory, The Miami Project to Cure Paralysis, and ${ }^{3}$ Departments of Cell \\ Biology and Anatomy and Neurological Surgery, University of Miami School of Medicine, Miami, Florida 33101, and \\ 2Centro de Biología Molecular "Severo Ochoa" (Consejo Superior de Investigaciones Cientificas), Facultad de Ciencias, \\ Universidad Autónoma de Madrid, Cantoblanco 28049 Madrid, Spain
}

The lack of axonal regeneration in the injured adult mammalian spinal cord leads to permanent functional impairment. To induce axonal regeneration in the transected adult rat spinal cord, we have used the axonal growth-promoting properties of adult olfactory bulb ensheathing glia (EG). Schwann cell (SC)filled guidance channels were grafted to bridge both cord stumps, and suspensions of pure (98\%) Hoechst-labeled EG were stereotaxically injected into the midline of both stumps, 1 $\mathrm{mm}$ from the edges of the channel. In EG-transplanted animals, numerous neurofilament-, GAP-43-, anti-calcitonin generelated peptide (CGRP)-, and serotonin-immunoreactive fibers traversed the glial scars formed at both cord-graft interfaces. Supraspinal serotonergic axons crossed the transection gap through connective tissue bridges formed on the exterior of the channels, avoiding the channel interior. Strikingly, after crossing the distal glial scar, these fibers elongated in white and periaqueductal gray matter, reaching the farthest distance analyzed $(1.5 \mathrm{~cm})$. Tracer-labeled axons present in SC grafts were found to extend across the distal interface and up to $800 \mu \mathrm{m}$ beyond in the distal cord. Long-distance regeneration (at least $2.5 \mathrm{~cm}$ ) of injured ascending propriospinal axons was observed in the rostral spinal cord. Transplanted EG migrated longitudinally and laterally from the injection sites, reaching the farthest distance analyzed $(1.5 \mathrm{~cm})$. They moved through white matter tracts, gray matter, and glial scars, overcoming the inhibitory nature of the CNS environment, and invaded SC and connective tissue bridges and the dorsal and ventral roots adjacent to the transection site. Transplanted EG and regenerating axons were found in the same locations. Because EG seem to provide injured spinal axons with appropriate factors for long-distance elongation, these cells offer new possibilities for treatment of CNS conditions that require axonal regeneration.

Key words: axonal regeneration; olfactory ensheathing glia; spinal cord injury; transplantation; immunohistochemistry; WGA-HRP
The peripheral nervous system (PNS) and CNS from adult mammals do not respond equally to lesions (Ramón y Cajal, 1928). Whereas injured axons in the PNS successfully grow and reestablish synaptic contacts with denervated targets (Ramón y Cajal, 1928; Fawcett and Keynes, 1990; Son et al., 1996), axonal regeneration in the CNS is abortive, leading to permanent loss of functions (Ramón y Cajal, 1928; Reier et al., 1983; Liuzzi and Lasek, 1987). The absence of axonal regeneration in the CNS has been related in part to the nonpermissive nature of the glial environment surrounding regenerating axons (Reier et al., 1983; Bovolenta et al., 1992). Oligodendrocytes, reactive astrocytes, and reactive microglial cells exert inhibitory influences on elon-

\footnotetext{
Received Dec. 22, 1997; revised Feb. 23, 1998; accepted Feb. 26, 1998.

This work was funded by the American Paralysis Association, National Institutes of Health Grant NS09923, and The Miami Project. A.R-C. was supported by the Human Frontier Science Program and The Miami Project. We thank E. Cuervo for generating SCs; C. Vargas for help with tissue processing; D. Santiago for animal care; M. Bautista, J. Belio, R. Camarena, and J. A. Pérez for photographic work; C. Rowlette for word processing; and A. Zazo for diagram drawings. We are also grateful to Dr. Patrick Aebischer (Centre Hospitaliés Universitairé Vaudois, Lausanne, Switzerland) and CytoTherapeutics, Inc. (Lincoln, RI) for gifts of PAN/PVC channels and Drs. Ian Dickerson (Department of Physiology and Biophysics) and Graham Wilkin (Imperial College, London, United Kingdom) for CGRP and GAP-43 antibodies, respectively. We thank Drs. W. D. Dietrich, N. Kleitman, and F. F. Santos-Benito for comments to improve this paper.

Correspondence should be addressed to Dr. Mary Bartlett Bunge, The Miami Project to Cure Paralysis, University of Miami School of Medicine, P.O. Box 016960, R-48, Miami, FL 33101.

Copyright (C) 1998 Society for Neuroscience $\quad 0270-6474 / 98 / 183803-13 \$ 05.00 / 0$
}

gation of mature axons and, thus, constitute a major obstacle to the process of axonal regeneration in the injured adult CNS (Liuzzi and Lasek, 1987; Bandtlow et al., 1990; Hatten et al., 1991; Bovolenta et al., 1992; Giulian, 1993; Schwab et al., 1993).

Although not all adult neurons exhibit the same regenerative potential, most of them regenerate their lesioned axons if the appropriate conditions are provided. Injured axons are able to grow for long distances through pieces of peripheral nerve grafted into the CNS (David and Aguayo, 1981; Hagg et al., 1990; Sauve et al., 1995). Schwann cells (SCs) produce a variety of neurotrophic and neurotropic factors, extracellular matrix, and adhesion molecules responsible for the growth-supporting properties of peripheral nerve (Bixby et al., 1988; Fawcett and Keynes, 1990; Raivich and Kreutzberg, 1993).

Several groups have used purified SC transplants to stimulate axonal elongation in different injured CNS regions (Kromer and Cornbrooks, 1985; Guénard et al., 1993; Montgomery and Robson, 1993; Harvey et al., 1994; Xu et al., 1995a, 1997). In transected spinal cords, SC-filled guidance channels may be grafted to bridge the gap created between the cord stumps (Xu et al., 1997). If these channels are provided with no other treatments, only axons from some sensory and propriospinal neurons enter and regenerate within them. When either neurotrophins (Xu et al., 1995b) or methylprednisolone (Chen et al., 1996) are administered concomitantly, however, some brainstem neurons also extend their axons into the grafts. Although numerous axons 
successfully grow inside SC-filled guidance channels, they fail to exit the grafts and, consequently, do not re-enter the CNS environment (Xu et al., 1997).

The failure of injured axons to regenerate within the mature CNS does not apply to the olfactory bulb. Normal and sectioned olfactory axons spontaneously grow within the adult olfactory bulb, establishing synaptic contacts with their targets (Graziadei and Monti Graziadei, 1980; Doucette et al., 1983). The major difference between a regenerating system such as the olfactory bulb and the rest of the CNS is the presence of ensheathing glia (EG) in the former (Doucette, 1991). Olfactory bulb EG display properties that may account for the permissiveness of adult olfactory bulb to axonal growth (Ramón-Cueto and Valverde, 1995; Ramón-Cueto and Avila, 1998). In fact, transplants of EG make possible the growth and elongation of dorsal root axons into adult rat spinal cords. These cells appear to migrate with regenerating axons through an unfavorable CNS environment, toward specific denervated cord laminae (Ramón-Cueto and Nieto-Sampedro, 1994). Very recently, Li et al. (1997) reported the recovery of forepaw motor function in adult rats with injured corticospinal tracts after transplantation of cells from olfactory bulb primary cultures. Here, we report that pure EG transplants enhance the regenerative effect of SC-filled guidance channels and, very strikingly, promote long-distance axonal regeneration within the adult rat spinal cord after complete transection.

\section{MATERIALS AND METHODS \\ Cell cultures}

\section{SC cultures and purification}

Pure cultures of SCs were obtained from sciatic nerves of adult Fischer rats (Charles River Laboratories, Wilmington, MA) as described previously (Morrissey et al., 1991). Briefly, sciatic nerves were dissected under sterile conditions, placed in $60 \mathrm{~mm}$ Petri dishes containing Leibovitz-15 medium (L-15; Gibco, Grand Island, NY), and divested of their epineurial sheaths. Nerves were chopped into $1 \mathrm{~mm}^{2}$ pieces and transferred to 35 mm Petri dishes containing DMEM (Gibco) supplemented with $10 \%$ fetal bovine serum (FBS; Hyclone laboratories, Logan, UT), 100 U/ml penicillin, and $100 \mu \mathrm{g} / \mathrm{ml}$ streptomycin (DMEM-10S). Nerve pieces were transferred to another $35 \mathrm{~mm}$ Petri dish every week for 5 weeks and were fed twice a week. After five transfers, explants were devoid of fibroblasts and contained only SCs. Explants were replated onto $35 \mathrm{~mm}$ Petri dishes with $1.25 \mathrm{U} / \mathrm{ml}$ dispase (Boehringer Mannheim, Mannheim, Germany), $0.05 \%$ collagenase (Worthington, Freehold, NJ), and 15\% FBS in DMEM and were incubated at $37^{\circ} \mathrm{C}$ in $5 \% \mathrm{CO}_{2}$ overnight. After incubation, explants were washed with DMEM-10S and dissociated, and the SCs were seeded onto poly-L-lysine-coated $100 \mathrm{~mm}$ Petri dishes at a density of $2 \times 10^{6}$ cells/dish. After $24 \mathrm{hr}$, the culture medium was changed to DMEM-10S supplemented with $2 \mu \mathrm{M}$ forskolin (Sigma, St. Louis, MO) and $20 \mu \mathrm{g} / \mathrm{ml}$ pituitary extract (Gibco). Cells, fed twice a week with this medium, were allowed to expand until confluency. The purified SCs were suspended in DMEM/Matrigel $(70: 30, v / v)$ to yield a final density of $120 \times 10^{6}$ cells/ml and were drawn into a guidance channel [polyacrylonitrile/polyvinyl chloride (PAN/PVC; from Dr. Patrick Aebischer and CytoTherapeutics, Inc., Lincoln, RI] with a $5 \mathrm{ml}$ syringe. The channel was then closed with PAN/PVC glue and kept overnight in DMEM at $37^{\circ} \mathrm{C}$ before transplantation.

\section{EG cultures and purification}

Primary olfactory bulb cultures were set up from adult female Fischer rats (four months old; Charles River Laboratories) as described previously in detail (Ramón-Cueto and Nieto-Sampedro, 1992). The method used to purify EG from primary cultures was modified from the original protocol (Ramón-Cueto and Nieto-Sampedro, 1994). Seven days after plating, EG were separated from other cell types in primary cultures by immunoaffinity, using an antibody against p-75 nerve growth factor receptor (p-75 NGFR; Developmental Hybridoma Bank, Iowa City, IA). Cells from primary cultures were detached with trypsin $(0.25 \% \mathrm{w} / \mathrm{v})$, centrifuged (200 g; $10 \mathrm{~min})$, and washed three times with D/F-10S (a 1:1 mixture of DMEM and Ham's F-12 media, supplemented with $10 \%$ FBS, $100 \mathrm{U} / \mathrm{ml}$ penicillin, and $100 \mu \mathrm{g} / \mathrm{ml}$ streptomycin). Cells were resuspended in D/F-10S and plated on $100 \mathrm{~mm}$ Petri dishes sequentially pretreated with antibodies as follows. Dishes were incubated with 1:1000 biotinylated anti-mouse IgG antibody (Jackson ImmunoResearch, West Grove, PA) for $12 \mathrm{hr}$ at $4^{\circ} \mathrm{C}$ and were washed with PBS, pH 7.3, three times. They were then incubated with supernatants of cultured 192 hybridoma cells containing p-75 NGFR at 1:1 dilution in PBS with 5\% bovine serum albumin (BSA) for $12 \mathrm{hr}$ at $4^{\circ} \mathrm{C}$. After washing with PBS, the dishes were incubated with PBS-5\% BSA for $4 \mathrm{hr}$ at room temperature. After dishes were washed with D/F-10S, $5 \mathrm{ml}$ of a suspension containing cells from olfactory bulb primary cultures was plated on the antibody-treated dishes, at a density of 300,000 cells per dish, for $45 \mathrm{~min}$ at $37^{\circ} \mathrm{C}$ in $5 \% \mathrm{CO}_{2}$. Unbound cells were removed, and the dishes were washed with $\mathrm{D} / \mathrm{F}$ without serum five times. Bound cells were detached from the dishes with a cell scraper (Costar, Cambridge, MA), centrifuged $(200 \mathrm{~g} ; 10 \mathrm{~min})$, and resuspended in D/F-10S. Cells obtained from three dishes were replated onto another antibody-treated Petri dish for $30 \mathrm{~min}$ at $37^{\circ} \mathrm{C}$ in $5 \% \mathrm{CO}_{2}$. As before, attached cells were removed with a cell scraper, centrifuged, and resuspended in $2.5 \mathrm{ml}$ of DMEM-10S. Cells were seeded onto a poly-L-lysine-treated (Sigma; average molecular weight, 30,000; $50 \mathrm{mg} / \mathrm{ml}) 25 \mathrm{~cm}^{2}$ flask (Costar) and were incubated at $37^{\circ} \mathrm{C}$ in $5 \% \mathrm{CO}_{2}$. After $24 \mathrm{hr}$, the culture medium was changed to DMEM-10S containing $2 \mu \mathrm{M}$ forskolin (Sigma) and $20 \mu \mathrm{g} / \mathrm{ml}$ pituitary extract (Gibco). Cells were cultured for $15 \mathrm{~d}$ at $37^{\circ} \mathrm{C}$ in $5 \% \mathrm{CO}_{2}$, and the culture medium was changed every $3 \mathrm{~d}$. Compared with previous cultures in which EG did not easily divide (Ramón-Cueto and Nieto-Sampedro, 1992, 1994; Ramón-Cueto et al., 1993), cultures of EG when forskolin and pituitary extract were added to the culture medium were able to expand. However, these two compounds may also increase the number of any non-EG-contaminating cells. To diminish the number of contaminating cells from EG cultures, we plated olfactory bulb cells onto antibody-coated dishes twice instead of once. The purity of EG cultures was checked $15 \mathrm{~d}$ after immunopurification and just before transplantation by counting p-75 NGFR-immunoreactive cells in the cultures (see below). The modification of the original protocol led to almost pure EG cultures (98\%) after $15 \mathrm{~d}$ in vitro.

\section{EG labeling}

Immunocytochemistry. EG cultures were immunocytochemically labeled with anti-p-75 NGFR to test the purity of the cultures. Fifteen days after immunopurification, cells were detached from the flasks with trypsinEDTA $(0.25 \% \mathrm{w} / \mathrm{v})$ and repeatedly washed by centrifugation with DMEM-10S. After the last centrifugation, 40,000 cells were resuspended in DMEM-10S, seeded on four poly-L-lysine-coated coverslips $(10,000$ cells per coverslip), and cultured for $24 \mathrm{hr}$ at $37^{\circ} \mathrm{C}$ in $5 \% \mathrm{CO}_{2}$. The remaining cells were labeled and transplanted as below. After $24 \mathrm{hr}$, cells cultured on coverslips were incubated with anti-p-75 NGFR for 45 min at $37^{\circ} \mathrm{C}$ in $5 \% \mathrm{CO}_{2}$, washed with DMEM-10S, and then treated with fluorescein-conjugated anti-mouse IgG antibody (Jackson ImmunoResearch; $1: 50$ dilution; $\left.45 \mathrm{~min} ; 37^{\circ} \mathrm{C} ; 5 \% \mathrm{CO}_{2}\right)$. Immunolabeled cultures were fixed with $4 \%$ paraformaldehyde $(10 \mathrm{~min}$; room temperature) and mounted. The proportion of EG in the cultures was determined by counting p-75 NGFR-immunoreactive cells under a fluorescence microscope and by comparing total cell counts of the same field under phase contrast microscopy.

Hoechst labeling. Fifteen days after immunopurification, EG were detached from the flasks (see above) and labeled with the nuclear fluorochrome bisbenzimide (Hoechst 33342; Sigma) (Baron-Van Evercooren et al., 1991). Cells were incubated for $30 \mathrm{~min}$ at $37^{\circ} \mathrm{C}$ in the dark in DMEM-10S containing $10 \mu \mathrm{g} / \mathrm{ml}$ bisbenzimide. They were rinsed three times with DMEM without serum, resuspended in the same medium at a density of 100,000 cells $/ \mu \mathrm{l}$, and then transplanted into the spinal cord.

\section{Surgical procedures}

\section{Transplantation technique}

Sixteen adult (4 months old) female Fischer rats (nine experimental and seven control rats; Charles River Laboratories) were anesthetized with a mixture of $\mathrm{O}_{2}: \mathrm{N}_{2} \mathrm{O}(40: 60)$. To prevent wound and bladder infections, antibiotics were given subcutaneously. An ophthalmic ointment was applied to the eyes to prevent drying.

$S C$ transplantation. The rats were placed onto a heating pad to maintain body temperature. A multilevel laminectomy was performed to expose T8-T10 thoracic spinal cord segments. The dura was cut longi- 


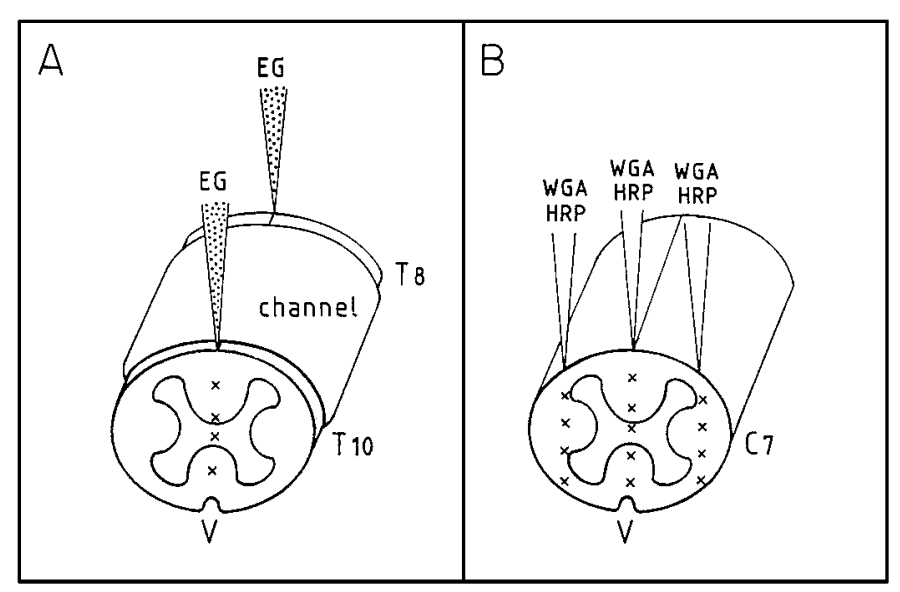

Figure 1. A, Diagram showing the four sites $(x)$ in the midline of both spinal cord stumps where suspensions of ensheathing glia $(E G)$ were grafted. $B$, Diagram illustrating the 13 spinal cord sites $(x)$ of cervical segment $7(C 7)$ where wheat germ agglutinin-horseradish peroxidase $(W G A-H R P)$ was injected 6 weeks after EG transplantation. $T 8$ and $T 10$, Thoracic segments 8 and $10 ; V$, ventral.

tudinally and laterally at proximal- and distal-most borders of the laminectomy. Lidocaine was administered onto the exposed spinal cord, followed by a transection at $\mathrm{T} 9$ and removal of a $4 \mathrm{~mm}$ segment. Dorsal roots were removed at the proximal and distal edges of the lesion site. A PAN/PVC channel $6 \mathrm{~mm}$ long [inner diameter (i.d.), $2.8 \mathrm{~mm}$; outer diameter (o.d.), $3.1 \mathrm{~mm}$, containing the SC and Matrigel mix, was carefully placed to allow the proximal and distal spinal cord stumps to be inserted $\sim 1 \mathrm{~mm}$ into the channel.

EG transplantation. Suspensions of Hoechst-labeled EG were stereotaxically injected with a sterile glass needle. Glass capillaries were pulled and needles (i.d., $80 \mu \mathrm{m}$; o.d., $100 \mu \mathrm{m}$ ) were obtained. They were sterilized by immersion in $80 \%$ ethanol for $4 \mathrm{hr}$ and by subsequent overnight exposure to UV light. Needles were connected to a sterile $5 \mu \mathrm{l}$ Hamilton syringe. The whole system was filled with sterile oil and mounted in a stereotaxic apparatus. Hoechst-labeled EG were loaded into the needles and stereotaxically injected into the midline of both spinal cord stumps, $1 \mathrm{~mm}$ from the edges of the channel (Fig. 1A). From ventral to dorsal, cells were injected in the following four sites of each cord stump: (1) ventral funiculus, (2) gray commissure, (3) dorsal corticospinal tract, and (4) gracile fasciculus. Coordinates (expressed in millimeters) of the four injection sites were $1.75,1.25,1$, and 0.5 , respectively. Each site received $0.5 \mu \mathrm{l}$ of a suspension containing 50,000 cells. Therefore, we injected 200,000 cells into each cord stump.

Control animals were grafted with SC-filled guidance channels as were experimental ones, but they did not receive EG injections. Instead, these animals were injected with $0.5 \mu \mathrm{l}$ of DMEM at the same spinal cord coordinates used in experimental rats.

After the operation, the exposed spinal cord was covered with Durafilm, the muscles and skin were sutured, and the wound was washed with an antiseptic solution. The rats received postoperative care including the subcutaneous injection of $10 \mathrm{ml}$ of lactated Ringer's solution and administration of Bicillin (20,000 U/d), and bladder expression for 7-10d. Six weeks after surgery, half of the animals were injected with the tracer, and the remaining rats were processed for immunohistochemistry.

\section{Tracing technique}

Six weeks after grafting, seven animals (four experimental and three control rats) were anesthetized, and their vertebral columns were opened between vertebrae $\mathrm{C} 5$ and $\mathrm{C} 7$, thereby exposing the lower half of $\mathrm{C} 6, \mathrm{C} 7$, and the upper half of $\mathrm{C} 8$ spinal cord segments. An aliquot $(0.05 \mu \mathrm{l})$ of $5 \%$ wheat germ agglutinin-horseradish peroxidase (WGA-HRP; Sigma) in $50 \mathrm{~mm}$ Tris- $\mathrm{HCl}$ buffer, $\mathrm{pH}$ 7.4, was stereotaxically injected using a sterile glass needle (i.d., $80 \mu \mathrm{m}$; o.d., $100 \mu \mathrm{m}$ ) connected to a sterile $5 \mu \mathrm{l}$ Hamilton syringe (same method that was used for EG transplantation). Tracer was injected at each of the following 13 coordinates in the rostral half of the C7 segment (Fig. 1B) (coordinates expressed in millimeters): in the midline: $1.85,1.45$ (ventral funiculus); 1.05 (gray commissure); 0.8 (dorsal corticospinal tract); and 0.4 (gracile funiculus); at $1.2 \mathrm{~mm}$ from the midline both to the left and to the right: 1.6, 1.2, 0.8, and 0.4 (all in the lateral funiculus). After $24 \mathrm{hr}$, animals were perfused and histologically processed for tetramethylbenzidine (TMB) labeling. The tracer WGA-HRP can be transported by axons in both anterograde and retrograde directions. To check the efficiency of WGA-HRP for tracing all spinal cord tracts using our method, three normal uninjured rats were subjected to the same protocol.

\section{Tissue processing}

After 6 weeks of survival, experimental and control animals were anesthetized and transcardially perfused with heparinized physiological saline followed by fixative.

\section{$W G A-H R P$}

Animals injected with tracer were perfused first with ice-cold heparinized physiological saline and then with $0.4 \%$ paraformaldehyde and $2 \%$ glutaraldehyde in $0.1 \mathrm{M}$ ice-cold phosphate buffer, $\mathrm{pH}$ 7.4. Spinal cords with guidance channels were dissected and post-fixed for $2 \mathrm{hr}$. After rinsing spinal cords with ice-cold $20 \%$ sucrose in PBS (1 hr), we incubated them in $30 \%$ sucrose and PBS overnight at $4^{\circ} \mathrm{C}$. Tissue was embedded in $10 \%$ gelatin and PBS $\left(3 \mathrm{hr} ; 37^{\circ} \mathrm{C}\right)$, and the gelatin block was fixed in $4 \%$ paraformaldehyde in PBS ( $2 \mathrm{hr}$; room temperature) and kept in $30 \%$ sucrose and PBS (overnight; $4^{\circ} \mathrm{C}$ ). The entire embedded spinal cords (with grafts and channels) were cut horizontally in a freezing microtome $(40 \mu \mathrm{m})$, and serial sections were collected in 24-well plates containing PBS. To label free-floating sections with TMB, we transferred the sections to a multiwell dish (Sigma) (Mesulam, 1978). Because TMB is not a substrate soluble in water, $5 \mathrm{mg}$ was heat dissolved in $2.5 \mathrm{ml}$ of warm $100 \%$ ethanol. After cooling to room temperature and for a short time at $4^{\circ} \mathrm{C}$, the TMB solution was combined with the cold $\left(4^{\circ} \mathrm{C}\right)$ prereaction mixture in a glass dish and agitated on a shaker for $20 \mathrm{~min}$. To this, $270 \mu \mathrm{l}$ of $3 \% \mathrm{H}_{2} \mathrm{O}_{2}$ was added. Sections were agitated again for 18-20 min until a dark reaction product could be detected in the sections. The stained sections were rinsed in three to four changes of prerinse solution to wash out nonspecific background staining, identified usually by a green discoloration. Stained sections were mounted onto gelatinsubbed slides (as above), left to dry, placed in xylene, and coverslipped using DPX. The slides were stored in a refrigerator because of the heat and light sensitivity of the TMB reaction product.

\section{Immunohistochemistry}

Immunostaining was performed on spinal cords that were not injected with WGA-HRP. Animals (five experimental, four control) were perfused with physiological saline and then with $4 \%$ paraformaldehyde in $0.1 \mathrm{M}$ ice-cold phosphate buffer, $\mathrm{pH} 7.4$, and spinal cords with guidance channels were dissected and post-fixed for $5 \mathrm{hr}$ at $4^{\circ} \mathrm{C}$. The tissue was kept in $30 \%$ sucrose in $0.1 \mathrm{M}$ phosphate buffer, $\mathrm{pH} 7.4$, for $36 \mathrm{hr}$ at $4^{\circ} \mathrm{C}$ and embedded in Gum Tragacant (Sigma)-PBS, and whole spinal cords were longitudinally cut (sagittal, $15 \mu \mathrm{m}$ sections) in a cryostat $\left(-20^{\circ} \mathrm{C}\right)$. Consecutive spinal cord sections were collected onto different gelatincoated glass slides, and each slide was immunohistochemically labeled or double-labeled with one or two different primary antibodies.

The following rabbit polyclonal primary antibodies were used in our study: anti-serotonin (5-HT; Incstar Corp., Stillwater, MN) (1:50), antidopamine- $\beta$-hydroxylase (D $\beta \mathrm{H}$; Incstar Corp.) (1:200), anti-calcitonin gene-related peptide (CGRP; provided by Dr. I. Dickerson) (1:100), anti-growth-associated protein-43 (GAP-43; a gift of Dr. Graham Wilkin) (1:200), anti-glial fibrillary acidic protein (GFAP; Dako, Carpenteria, CA) (1:100), and S100 antibody (Dako) (1:200). We also used mouse monoclonal IgG against neurofilaments (RT-97; Developmental Hybridoma Bank) (1:5) and anti-ED1 (Serotec, Indianapolis, IN), a mouse monoclonal IgG (1:200). Fluorescein-conjugated goat anti-mouse or rhodamine-conjugated goat anti-rabbit (Jackson ImmunoResearch) Igs were used as secondary antibodies at 1:100 and 1:80 dilutions, respectively. To diminish background labeling, we preincubated secondary antibodies with other spinal cord tissue from experimental rats before immunostaining.

Sections were washed three times with PBS and incubated with $0.1 \%$ Triton X-100 (Sigma) with $1 \%$ normal goat serum in $0.1 \mathrm{M}$ phosphate buffer, $\mathrm{pH} 7.4$, for $30 \mathrm{~min}$ at room temperature. Incubations with antiserotonin antibody were performed for $45 \mathrm{~min}$ at room temperature; incubations with the other primary antibodies were performed overnight at $4^{\circ} \mathrm{C}$. After repeated washing with PBS, sections were incubated with their respective secondary antibodies for $45 \mathrm{~min}$ at room temperature, 

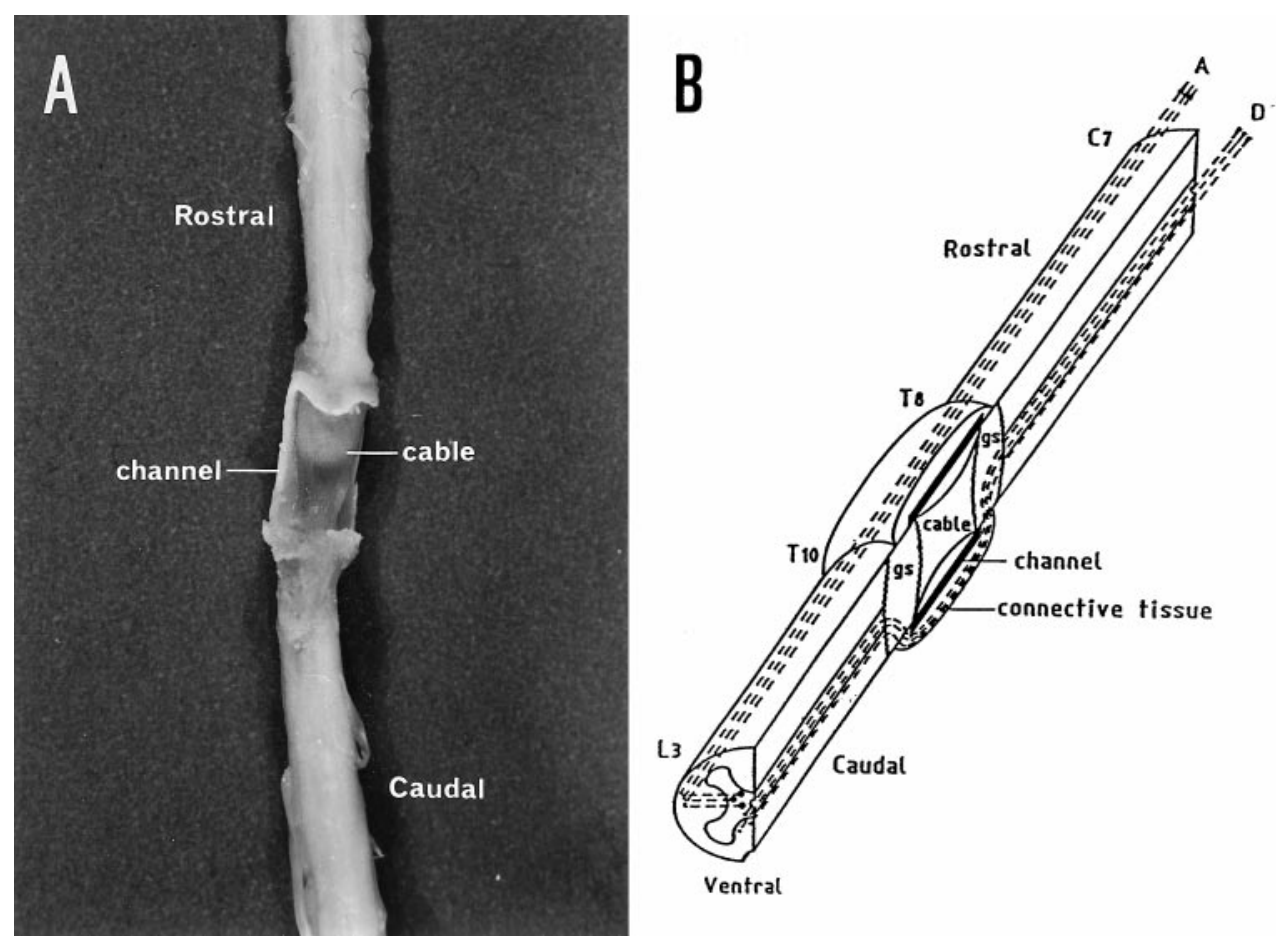

Figure 2. A, Dorsal surface of a perfused EG-transplanted spinal cord 6 weeks after surgery. To expose the SC cable, we removed the dorsal part of the channel. The cable was firmly attached to both rostral and caudal spinal cord stumps. $B$, Diagram showing a sagittal hemisection of a grafted spinal cord 6 weeks after transplantation. Two bridges were present between rostral and caudal cord stumps: (1) a SC- and EG-containing cable inside the channel and (2) a connective tissue layer containing EG around the channel. Dashed lines represent regenerating ascending $(A)$ and some of the descending $(D)$ fibers. Because of space constraints, the ascending fibers and some of the descending fibers were not drawn through the SC bridge. C7, Cervical segment 7; gs, glial scar; $L 3$, lumbar segment $3 ; T 8$ and $T 10$, thoracic segments 8 and 10 .

washed with PBS, coverslipped, and examined in a fluorescence microscope (Zeiss Axiophot).

\section{RESULTS}

EG transplants were used in combination with SC-filled guidance channels to test their effect on regenerative axonal growth in the transected adult rat spinal cord. Six weeks after surgery, thick SC-containing cables were present inside the channels of all transplanted animals (Fig. $2 A$ ), and they were firmly attached to the rostral and caudal spinal cord stumps, forming a bridge between them. A thin layer of connective tissue surrounded the outer surface of the channels and connected lateral regions of both spinal cord stumps, also forming a bridge between them (see Figs. $2 B, 3 C$ ). Therefore, there were two types of bridges between the spinal cord stumps, a SC-containing bridge inside the guidance channel and a connective tissue bridge on the channel exterior. Using immunohistochemical and peroxidase-labeling techniques, we observed that injured axons entered and elongated inside both types of bridges to reach the opposite cord stump (see Figs. 3, 7). Moreover, regenerating axons were able to exit these bridges, crossing the gliotic tissue at both cord-graft interfaces, and to grow rostrally and caudally through the milieu of the spinal cord stumps.

\section{Composition of bridges}

In addition to SCs and Matrigel, the cables inside the channels contained EG and axons as revealed by Hoechst labeling and either neurofilament or GAP-43 immunolabeling (Fig. $3 A, B$ ). Intense immunoreactivity was observed in the entire width of the cables (Fig. $3 A$ ). Hoechst and neurofilament or GAP-43 labeling showed that connective tissue bridges contained EG and axons (Fig. $3 C, D$ ). In some regions of both types of bridges, EG appeared to be aligned along immunoreactive axons (compare Fig. $3 A$ and $C$ with $B$ and $D$, respectively).

The absence of GFAP immunoreactivity inside the bridges showed that astrocytes did not migrate into either type of bridge (Fig. $4 A, F$ ). The majority of ED1-immunoreactive cells (macro- phages and microglia) were found at the cord transection sites outside both bridges. Occasionally in some sections, however, some ED1-immunoreactive cells could be seen entering the cables (Fig. 4B). Astrocytes and macrophages and microglial cells created a glial scar at both rostral and distal cord-cable interfaces (Fig. 4A, $B, F)$. Gliotic tissue at both interfaces contained Hoechst-labeled nuclei, showing that EG were a constituent of the glial scars (Fig. 4C,H). Moreover, EG intermingled with the astrocytes and microglial cells, indicating that these cells did not exert an inhibitory influence on EG migration.

In summary, cables inside guidance channels contained Matrigel, SCs, EG, and axons, whereas the connective bridges on the channel exterior contained fibroblasts, EG, and axons. Both types of bridges were devoid of astrocytes.

\section{Axonal regeneration}

\section{Immunohistochemical analysis}

Numerous GAP-43- and neurofilament-immunoreactive axons were observed to have regenerated across glial scars formed at both graft-cord interfaces and to have entered both types of bridges. Axons crossed the interfaces created between the spinal cord stumps and either SC-containing cables or connective tissue bridges (Figs. $3 A, C, 4 D, E, G$ ). Hoechst-labeled EG and regenerating axons were observed in the same regions of the rostral and caudal gliotic tissue and interfaces, SC cables, and connective tissue bridges (compare Figs. $3 A$ and $C$ with $B$ and $D, 4 D$ and $E$ with $C, 4 G$ with $H$ ). Also in those locations, some Hoechststained nuclei were found aligned along the axons, suggesting an association between the two (Fig. 3). Anti-GAP-43 and antineurofilament antibodies recognized numerous axonal profiles throughout the gray and white matter of rostral and caudal spinal cord stumps (data not shown).

To identify some of the regenerated axons (descending, ascending, or cell type), we used antibodies against CGRP, serotonin, and $\mathrm{D} \beta \mathrm{H}$, as well as WGA-HRP tracing. Anti-CGRP labels ascending sensory axons from DRG neurons as well as processes 

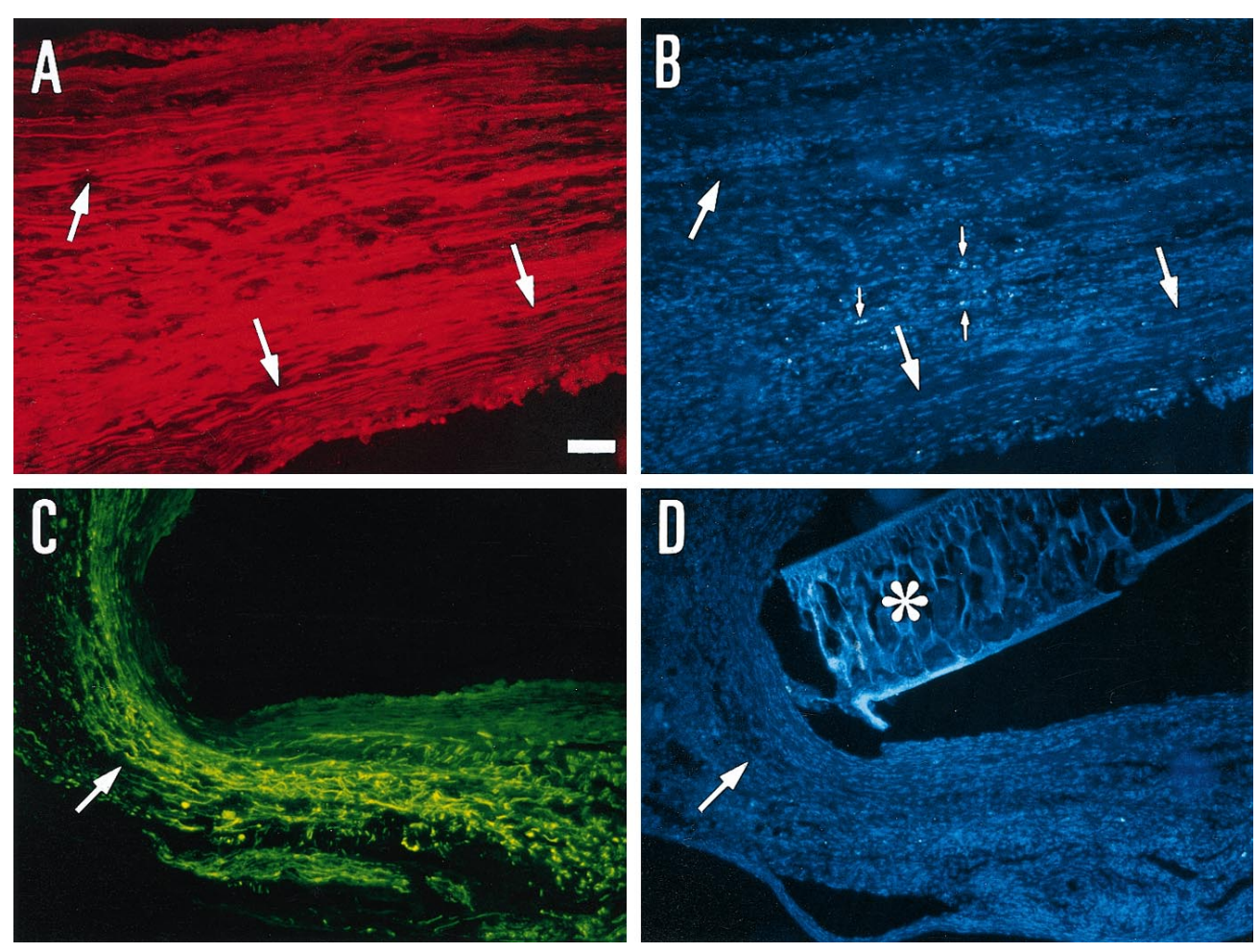

Figure 3. Regenerating axons growing inside either an SC- and EG-containing cable $(A, B)$ or an EG-containing connective tissue bridge $(C, D)$. $A$, Regenerating axons visualized by immunolabeling with anti-GAP-43 antibody. $B$, Hoechst-labeled EG observed in the same field shown in $A$. $C$, Regenerating axons immunolabeled with antineurofilament antibody. $D$, Hoechstlabeled EG present in the same field shown in $C$. Large arrows point to EG $(B, D)$ aligned along bundles of regenerating axons $(A, C)$. Small arrows in $B$ point to Hoechst-labeled nuclei of macrophages and microglial cells. Note the difference in shape and color of these cells compared with that of EG. A portion of the channel, which autofluoresces with the filter used, was retained in $D$ (asterisk). Scale bar, $60 \mu \mathrm{m}$. of motor neurons (Gibson et al., 1984), and antibodies against serotonin and $\mathrm{D} \beta \mathrm{H}$ recognize descending fibers from raphe and locus coeruleus neurons, respectively (Newton and Hamill, 1988, 1989). CGRP-positive axons from the dorsal columns crossed the distal glial scar dorsally (Fig. 5A,B), elongated into either SCcontaining cables (Fig. $5 C$ ) or connective tissue bridges (Fig. $5 D$ ), and were observed at the rostral cord-cable interface (Fig. $5 E, F)$. These fibers did not show any preference for a specific type of bridge or a specific location inside the bridges; they invaded the entire width and length of both bridges (Fig. 5C,D). Although CGRP-immunostained axons were detected in rostral spinal cord stumps, it was difficult to establish their origin; they could be either regenerated fibers, unlesioned sensory axons entering the rostral cord, or both.

Although serotonin-immunoreactive fibers crossed the rostral gliotic tissue and reached the proximal cord-SC cable interface (Fig. 6A,B), they did not extend inside the SC-containing cables in order to cross the gap between the stumps. Instead, they regenerated through the EG-containing connective tissue surrounding guidance channels (Fig. 6D). Although a few serotonergic axons traversed the $\mathrm{SC}$-cord cable interface at its ventral outermost aspect, they were found exclusively at the periphery of the cables where an epineurium-like layer is typically found ( $\mathrm{Xu}$ et al., 1995a) (Fig. 6C). Moreover, because the distance traveled by these fibers did not exceed $1 \mathrm{~mm}$, they did not reach the distal cord-cable interface. Serotonin-immunoreactive axons reached the distal cord-cable interface through the connective tissue bridge, crossed the gliotic tissue of the caudal spinal cord stump (Fig. $6 E-G$ ), and grew into the cord beyond (Fig. $6 H-K$ ). Serotonergic axons were encountered in the ventral columns (Fig. 6H) and periaqueductal gray matter (Fig. $6 I$ ) of the distal spinal cord, at the farthest distance analyzed $(1.5 \mathrm{~cm})$. Occasionally, a spray of small serotonin-immunoreactive dots was observed delineating some motor neurons in the ventral horn of distal spinal cord (Fig. $6 K$ ). EG and serotonergic axons were observed in the same distal spinal cord regions (compare Fig. $6 I$ and $K$ with $J$ and $L$, respectively).

In contrast to serotonergic fibers, other neuronal types appeared to elongate their axons in either type of bridge. The total number of neurofilament- and GAP-43-immunoreactive fibers inside the SC cables was much higher than was the number of CGRP-stained fibers. Although many of them were propriospinal axons (see next section), the specific nature of the rest remains to be determined. Noradrenergic axons were detected at the rostral cord-cable interface, but they did not regenerate beyond the glial scar and did not enter bridges of either type (data not shown).

In control animals, regenerating neurofilament- and GAP-43immunopositive axons were observed to enter SC-containing cables, but the extent of axonal regeneration appeared less than that of EG-transplanted cords. Moreover, in control animals, few CGRP and no serotonergic fibers crossed the cord-bridge interfaces and extended into grafts. As in EG-transplanted animals, noradrenergic axons reached the proximal cord-SC cable interface but did not regenerate into the bridges. Interestingly and different from EG-transplanted animals, axonal elongation inside connective tissue bridges was not observed in control animals.

\section{WGA-HRP tracing}

To establish the efficiency of the tracing protocol, WGA-HRP was injected into unlesioned spinal cords at 13 different sites in the C7 segment (see Materials and Methods). All descending and ascending cord tracts transported the tracer in anterograde and retrograde directions, and we observed retrogradely labeled so- 

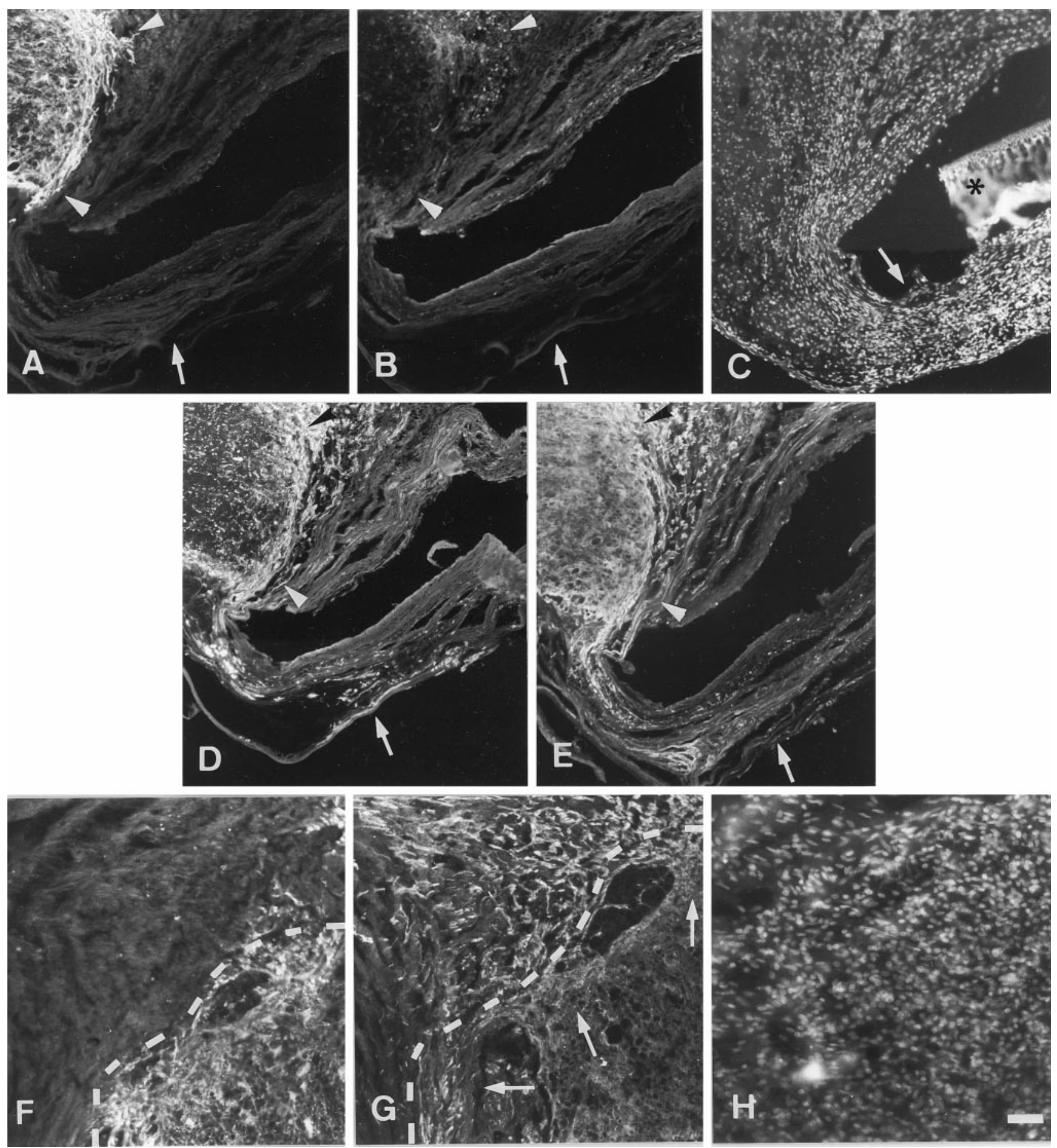

Figure 4. Regenerating axons crossing the gliotic tissue created at both graft-cord interfaces after EG transplantation. $A-E$, Consecutive spinal cord sagittal sections showing the interfaces between the rostral cord stump and either SC and EG cables or EG connective tissue bridges. Sections were immunolabeled for GFAP $(A)$, ED1 $(B)$, neurofilament $(D)$, and GAP-43 $(E)$. EG were visualized by Hoechst labeling $(C)$. A portion of the channel, which autofluoresces with the filter used, was retained in $C$ (asterisk). Arrowheads in $A, B, D$, and $E$ point to the cord-cable interface; arrows in $A-E$ mark the EG-containing connective tissue bridge. $F-H$, Consecutive spinal cord sections showing the caudal cord-cable interface. Dashed lines $(F, G)$ indicate the interface. Sections were immunolabeled for GFAP $(F)$ and GAP-43 $(G)$. Hoechst-labeled EG $(H)$ are in the same region shown in $F$. Arrows in $G$ point to GAP-43-labeled fibers crossing the cord-cable interface and in the gliotic tissue. Note the presence of EG in the gliotic tissue of both interfaces $(C, H)$ and in both SC-containing cables and connective tissue bridges $(C)$. Scale bars: $A-E, 125 \mu \mathrm{m} ; F-H, 90 \mu \mathrm{m}$.

mata at all spinal cord segments located below the WGA-HRP injection site (data not shown). The same method was performed in four experimental and three control animals.

Both experimental and control rats showed the presence of a cable, bridging the proximal and distal spinal cord stumps. In all of the traced experimental rats, Hoechst-labeled EG were found in both the proximal and distal spinal cord stumps, SC cables, and connective tissue bridges. The position and distances traveled by 

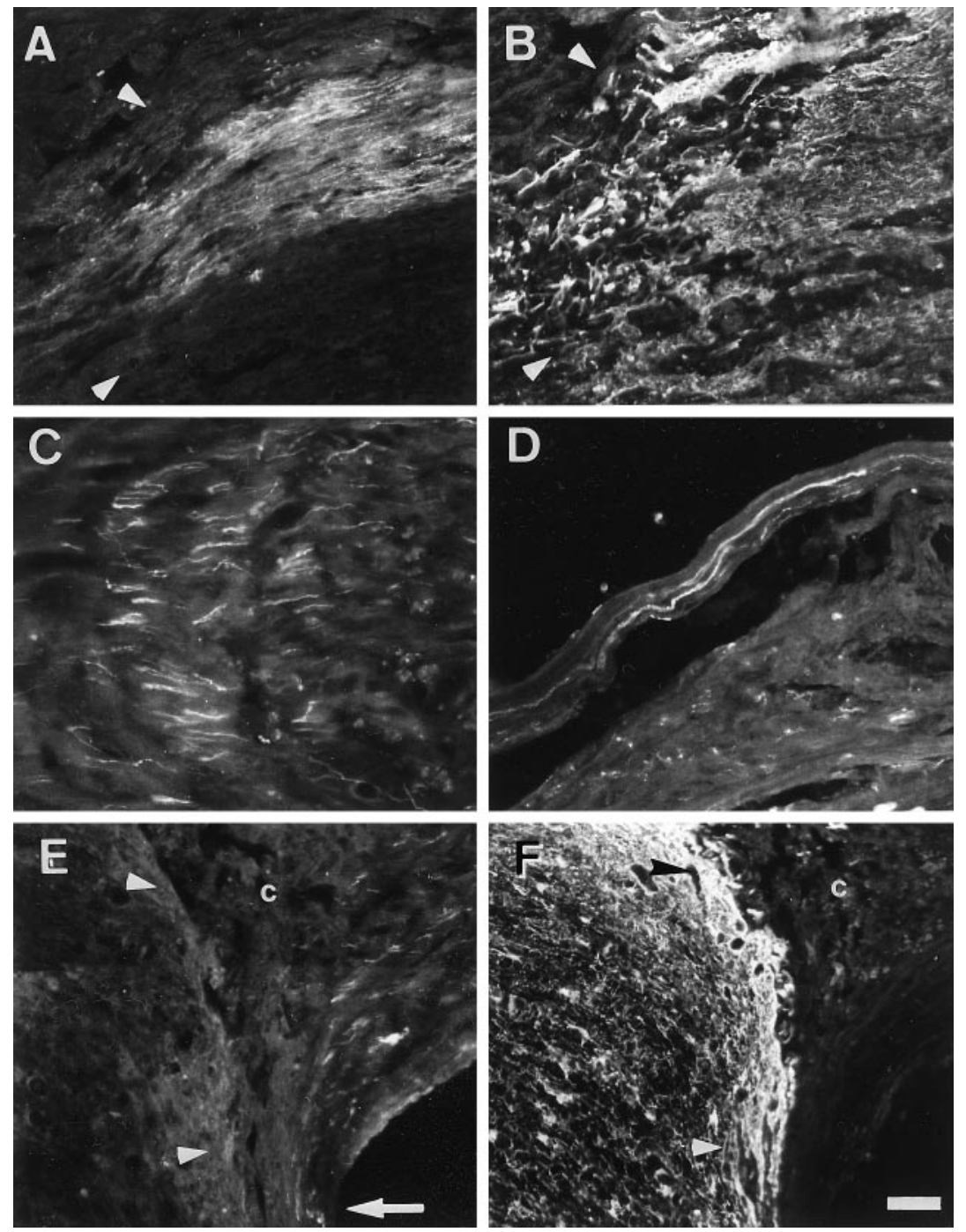

Figure 5. Regeneration of CGRP-positive fibers in the transected spinal cord after EG transplantation. $A, B$, Consecutive spinal cord sections showing CGRPimmunoreactive fibers $(A)$ crossing the GFAP-positive gliotic tissue $(B)$ at the caudal cable-cord interface (arrowheads) from the dorsal columns. C, D, CGRPpositive fibers regenerating through an SC and EG cable $(C)$ or a bridge of EG connective tissue $(D) . E, F$, Consecutive sections immunolabeled for CGRP $(E)$ or GFAP $(F)$. $E$ shows CGRP-immunoreactive axons growing inside an SC- and EG-containing cable $(c)$ and a connective tissue bridge (arrow), near the glial scar of the rostral interface (arrowheads in $E$ and $F$ ). Scale bars: $A, B, 85 \mu \mathrm{m}$; $C, D, 50 \mu \mathrm{m} ; E, F, 90 \mu \mathrm{m}$. the Hoechst-labeled EG resembled those seen in the immunohistochemically analyzed animals.

WGA-HRP tracing, visualized by TMB histochemistry, showed the presence of labeled regenerating axons that had entered, grown through, and exited the SC cable into the distal spinal cord in three of the four experimental rats. Large numbers of axons were seen to enter the rostral region of the SC cable (Fig. $7 A$ ). Although a substantial number, there were somewhat fewer labeled axons near the distal end of the SC cable compared with the proximal end. TMB-labeled axons entered the distal spinal cord for up to $800 \mu \mathrm{m}$ from the distal interface (Fig. $7 B, C$ ). These axons entered the distal cord via the gray matter; no axons were seen to enter the distal white matter. The average length of the TMB-labeled regenerated axons from the interface was 480 $\mu \mathrm{m}$. The axons were in dense tracts. In contrast, no axons were seen to enter the distal gray or white matter of the control rats (Fig. 7D).

Three of the four experimental rats also exhibited the presence of labeled spinal neurons in the distal gray matter (Fig. $7 E-H$ ). A maximum number of $26 \mathrm{TMB}$-labeled neurons was found in one of the experimental cords, 21 in another, with the lowest number being 7; the average was 18 labeled neurons in the distal gray matter. These TMB-labeled neurons were seen at long distances from the distal interface, with one rat showing labeled neurons at a distance of $1.9 \mathrm{~cm}$ (Fig. $7 H$ ). The majority of the TMB-labeled neurons were found between 0.5 and $3 \mathrm{~mm}$ from the distal interface in segments T10-T11 of the distal spinal cord and in laminae V and VII (Fig. 7E). However, some of these labeled neurons were also found in spinal segments L1-L3 and, again, within laminae V (Fig. $7 F$ ) and VII (Fig. $7 G, H$ ).

\section{Ensheathing glia migration}

The distribution of Hoechst-labeled EG was analyzed in all consecutive spinal cord sections from transplanted animals (Fig. 8). Hoechst-labeled nuclei were round or elongated with smooth borders. They displayed uniform staining and showed an absence of chromatin condensation or fragmentation. The labeling pattern and the lack of small aggregates of DNA indicated that Hoechst-labeled cells were alive and corresponded to EG (Crowe et al., 1997). Clearly, some macrophages had taken up the Hoechst dye, but their appearance was very different (Fig. 3B). Also, many cells in regions containing Hoechst-labeled nuclei were devoid of Hoechst labeling, indicating that the dye was not transferred to cell types other than macrophages. 

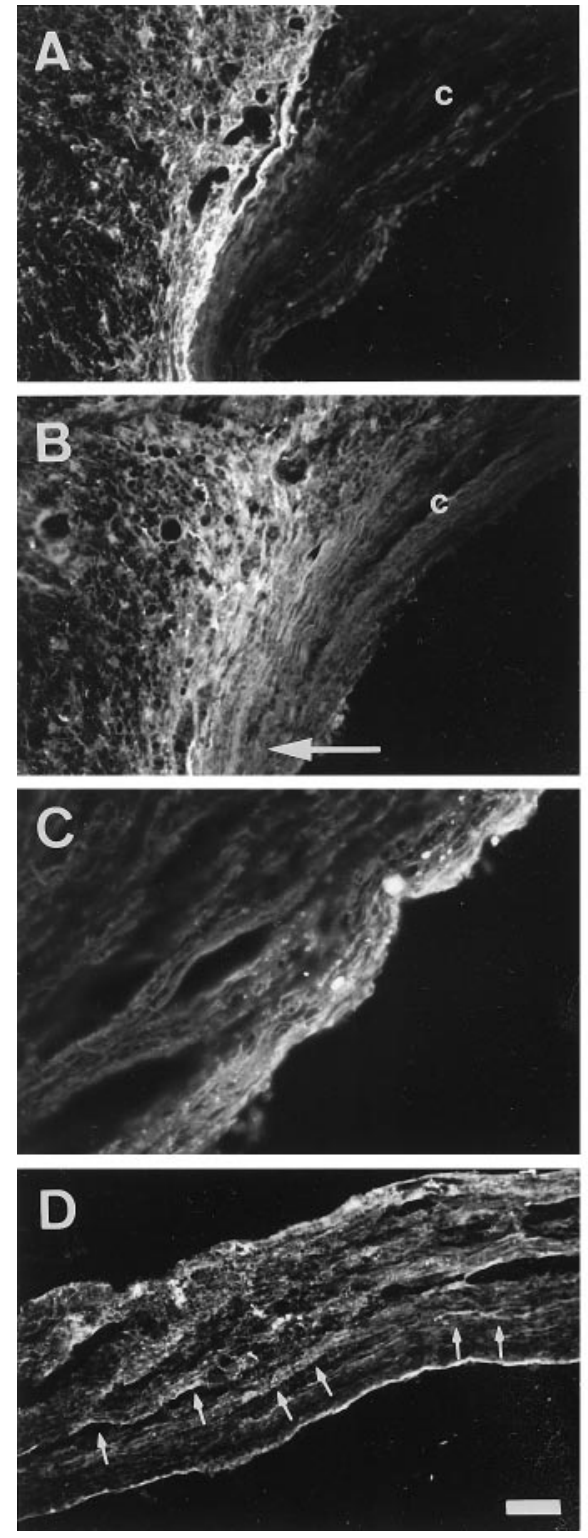
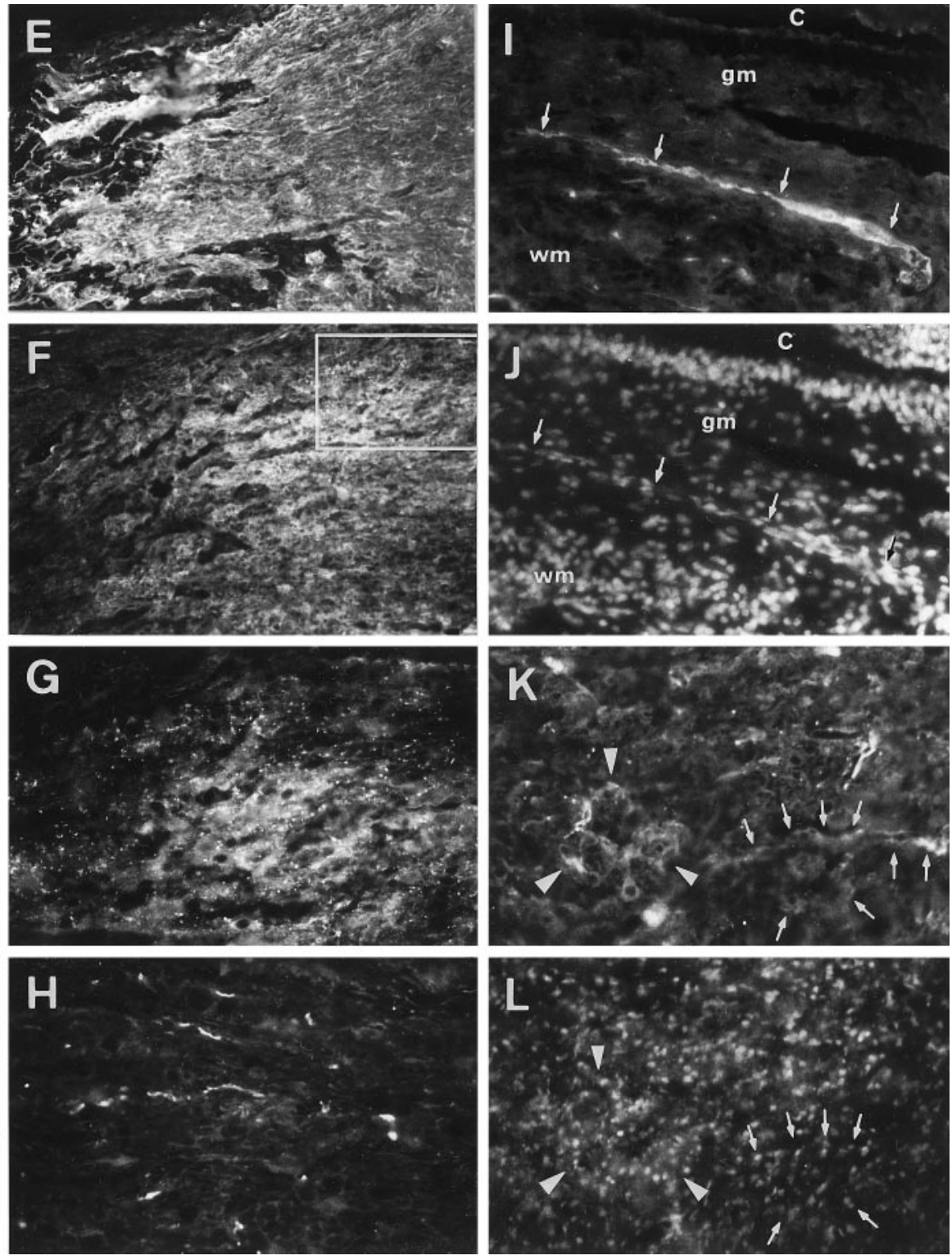

Figure 6. Regeneration of serotonergic axons after EG transplantation. $A, B$, Consecutive spinal cord sections immunolabeled for GFAP ( $A$ ) and serotonin $(B)$. Serotonergic fibers grow through the GFAP-positive gliotic tissue at the rostral transection site and reach the rostral cord-cable. Most fibers grow ventrally toward the connective tissue that surrounds the channel (arrow). $c$, Cable. $C$, Serotonergic axons at the periphery of an SC and EG cable $1 \mathrm{~mm}$ from the cord-cable interface. $D$, Serotonergic axons (arrows) regenerating through the EG-containing connective tissue surrounding the channel. $E, F$, Consecutive spinal cord sections immunolabeled with anti-GFAP $(E)$ and anti-serotonin $(F)$ showing serotonergic fibers in the glial scar of the caudal stump. $G$, Higher magnification of the serotonergic fibers in the boxed region in $F$. $H$, Serotonergic axons regenerating through the ventral columns at the L2 level. I, Section of the distal spinal cord at the level of L2 immunolabeled for serotonin. $J$, Hoechst-labeled EG in the same field shown in $I$. Arrows $(I, J)$ point to one serotonin-immunostained axonal bundle at the periaqueductal gray matter $(\mathrm{gm})$ bordering the white matter $(\mathrm{wm})$ of the ventral columns. Note the close association of the fibers and EG (compare arrows in $I, J$ ). $c$, Central canal. $K$, Serotonin-immunoreactive fibers in the ventral horn of the caudal cord stump. Note that some immunopositive fibers delineate the dendrites and bodies of neurons; arrows point to a neuron the dendrites and body of which are outlined by serotonergic immunoreactivity, and arrowheads point to serotonin immunostaining surrounding a group of neurons. $L$. Same field shown in $K$ revealing Hoechst-labeled EG. The Hoechst-labeled nuclei colocalize with the serotonergic fibers associated with the neurons shown in $K$ (arrows and arrowheads). Scale bars: $A, B$, $E, F, I, J, 100 \mu \mathrm{m} ; C, 50 \mu \mathrm{m} ; D, 90 \mu \mathrm{m} ; G, H, K, L, 45 \mu \mathrm{m}$.

Injected EG migrated longitudinally and laterally from the injection sites in both cord stumps. They moved rostrally and caudally, crossing gliotic tissue (Fig. $4 C, H$ ), entering both types of bridges (Figs. $3 B, D, 4 C, H$ ), and invading proximal and distal spinal cord stumps for the farthest distances analyzed (Fig. 8A,C) (1.5 cm from both cord-cable interfaces). Labeled EG were located in the gracile and cuneate fasciculi, dorsal corticospinal tract, ventral columns (Fig. 8D), and the medial part of the lateral funiculus (Fig. $8 A, C$ ). This indicated that EG were able to move through white matter tracts. EG were also present in the medial and paramedial gray matter along all segments studied (Figs. 6J, 8B). Laterally, EG migrated $0.8 \mathrm{~mm}$ from the midline, invading the medial portion of the lateral columns along the entire cord (Fig. 8A,C). EG were also detected at the pia mater of those cord regions containing EG just beneath the cord surface (Fig. $8 C, D$ ). They were also 

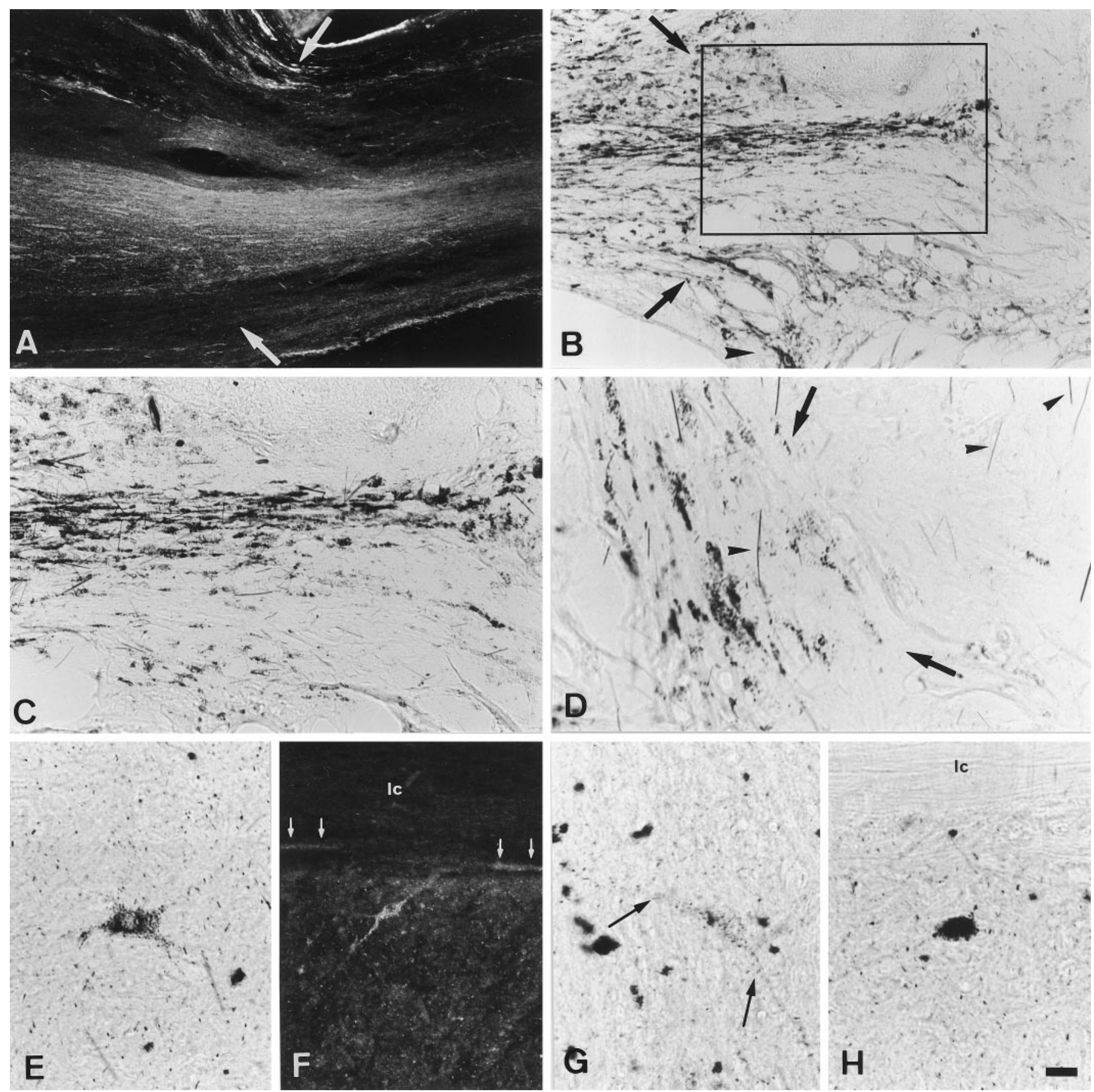

Figure 7. Photomicrographs of WGA-HRP tracing visualized by TMB histochemistry in experimental and control animals. Spinal cords were cut in the horizontal direction. $A$, Dark-field photograph showing labeled axons entering an SC- and EG-containing cable. Arrows point to the rostral cord (left)-cable (right) interface. B, Bright-field photograph illustrating labeled axons entering the caudal spinal cord stump. Arrows indicate the cable (left)-host (right) interface. The arrowhead points to labeled axons growing through the connective tissue bridge surrounding the channel. $C$, Higher magnification of boxed area in $B$ showing the regenerating axons entering the caudal cord stump. $D$, In control animals, labeled axons are seen in the distal-most region of the cable but not in the distal cord stump. The cable (left)-cord (right) interface is marked by arrows. Arrowheads indicate nonspecific TMB crystals. $E-H$, Photomicrographs of neurons retrogradely traced with WGA-HRP in the caudal cord stump. $F$ is a dark-field and $E$, $G$, and $H$ are bright-field photomicrographs. Labeled neurons are in lamina V of T11 $(E)$ and L1 $(F)$ cord segments. Arrows in $F$ point to labeled axons running in the lateral columns $(l c)$. Labeled neurons are in lamina VII of L1 $(G)$ and L3 $(H)$ cord segments. The processes (arrows) but little of the cell body of the neuron are present in the section shown in $G$. In $H$, the labeled neuron is located near the lateral columns $(l c)$. Scale bars: $A, B, 160 \mu \mathrm{m}$; $C, F, 80 \mu \mathrm{m} ; D, 50 \mu \mathrm{m} ; E, G, H, 40 \mu \mathrm{m}$.

observed along the ependymal layer along the entire cord length (Figs. 6J, 8B). Dorsal and ventral roots from the two segments above and below the transection site also contained Hoechst-labeled EG (Fig. 8C,D). All other spinal cord regions were devoid of EG. The pattern of EG distribution suggests that neither gray nor white matter exerted an inhibitory influence on EG migration. Moreover, neither connective nor gliotic tissue hindered EG migration. Also, because these cells 
Figure 8. EG migration through the transected spinal cord visualized by Hoechst nuclear labeling. $A$, Labeled nuclei in the lateral columns of the caudal cord stump. The arrowhead points to a distance of $1.5 \mathrm{~cm}$ caudal to the edge of the guidance channel, the farthest distance analyzed. $B$, Labeled EG nuclei in the ependymal layer (arrow) and the periaqueductal gray matter of the caudal cord stump. $C, D$, Labeled EG nuclei in a dorsal root (arrows in $C$ ) and a ventral root (arrows in D). $d h$, Dorsal horn; $l c$, lateral column; $v c$, ventral column. The arrowhead in $C$ points to a distance of $1.5 \mathrm{~cm}$ rostral to the edge of the channel, the farthest distance analyzed. Notice that some regions lack Hoechst-labeled nuclei (see top half in $B$, lateral columns in $C$, and ventral columns and root in $D$ ). Scale bars: $A, C, D$, $100 \mu \mathrm{m} ; B, 50 \mu \mathrm{m}$.
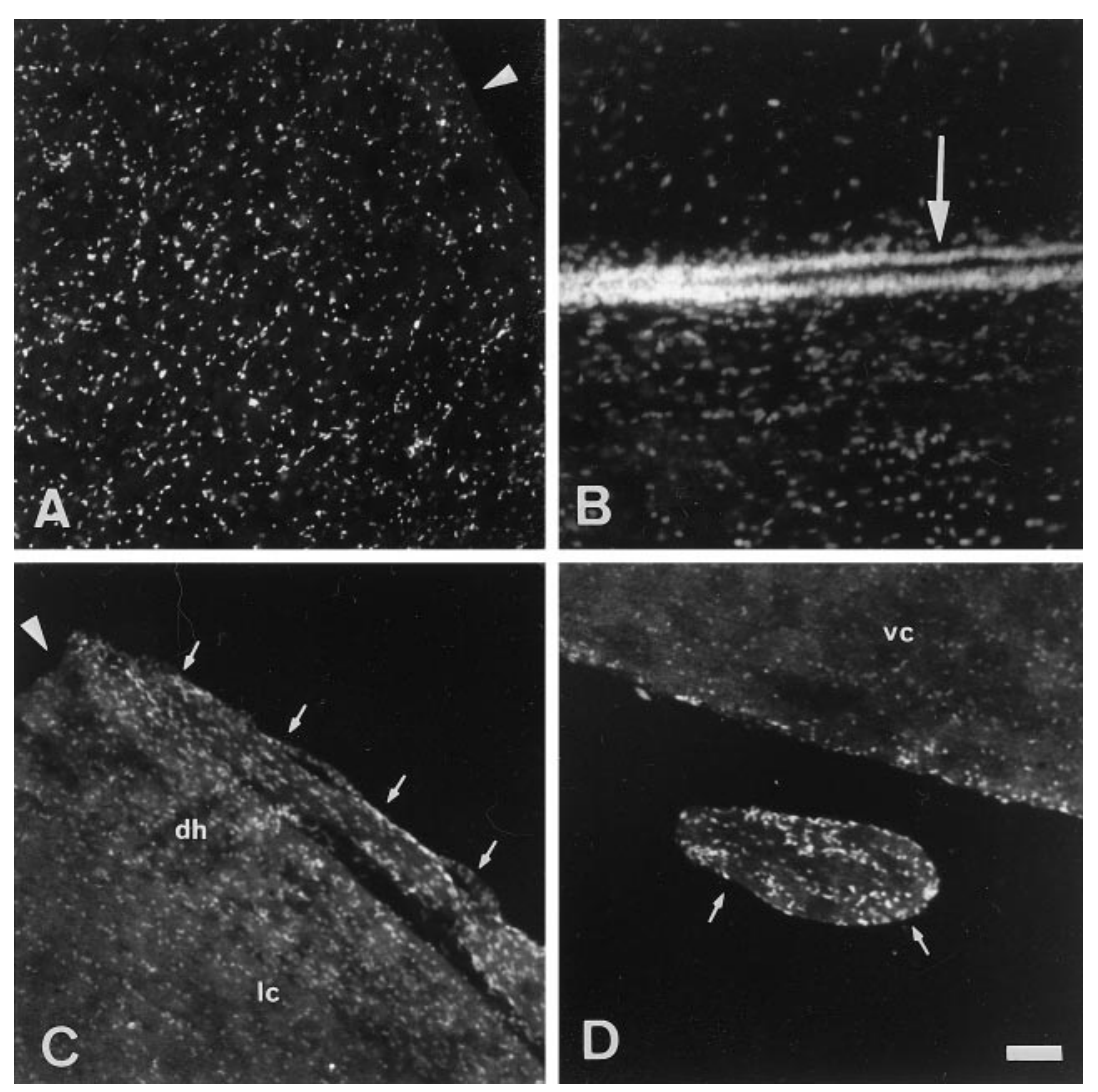

exited the CNS and migrated into peripheral nerves, EG migration appeared not to be restricted to the CNS.

\section{DISCUSSION}

Numerous attempts have focused on finding new strategies leading to axonal regeneration in the injured adult mammalian cord (e.g., David and Aguayo, 1981; Schnell et al., 1994; Tuszynski et al., 1994; Bregman et al., 1995; Xu et al., 1995a; Cheng et al., 1996; Kalderon and Fuks, 1996; Oudega and Hagg, 1996; Guest et al., 1997; Xu et al., 1997; Ye and Houle, 1997, Menei et al., 1998). In this context, we previously demonstrated that SC-filled guidance channels provide a useful tool to enhance the extent of axonal regeneration in transected cord (Xu et al., 1995a,b, 1997; Chen et al., 1996). Whereas regenerating axons successfully entered the channels, they were unable to elongate into the milieu of the spinal cord stumps beyond. It has recently been reported that EG transplants foster the regeneration of dorsal root and corticospinal axons within the adult rat spinal cord, after they have been injured selectively (Ramón-Cueto and Nieto-Sampedro, 1994; Li et al., 1997). In the present study, we combined the use of SC-filled guidance channels with EG transplants to test the axonal growth-promoting ability of EG in the adult rat spinal cord after complete transection. Using this experimental paradigm, we observed that EG not only elicited a robust ingrowth of injured axons into the channels but, strikingly, also improved growth across graft-cord interfaces and promoted long-distance regeneration of descending supraspinal and ascending propriospinal axons within both cord stumps.

\section{EG transplants promote long-distance axonal regeneration of injured raphe neurons}

In the control animals evaluated here, there was no serotonergic axonal regeneration from raphe neurons into SC grafts. In pre- vious work (Xu et al., 1997), 5-HT-immunoreactive fibers were seen to extend short distances (up to $0.7 \mathrm{~mm}$ ) into the rostral end of the SC graft. This was the result observed in the experiments described here in which animals were grafted with both SC-filled guidance channels and EG. Most serotonergic fibers, however, regenerated through connective tissue on the channel exterior when EG were transplanted. Other neuronal types (sensory, propriospinal) elongated axons inside cables or connective tissue, implying that, unlike other regenerating neurons, serotonergic axons preferred the environment created by fibroblasts and EG. Moreover, although some serotonergic axons invaded the thin connective tissue layer at the perimeter of SC cables, they elongated for only a short distance as mentioned above, suggesting that the environment created by fibroblasts, SCs, or both was inadequate for their elongation. Either EG or fibroblasts alone seemed to be necessary but not sufficient to promote regeneration of serotonergic fibers. Although regeneration occurred in the presence of EG, it was less in EG- and SC-containing cables. Furthermore, these fibers failed to grow through connective tissue lacking EG in control animals. Therefore, EG and fibroblasts together seemed to provide an adequate combination of factors needed for axonal regeneration of raphe neurons.

In undamaged spinal cords, most serotonergic fibers descend from brainstem raphe neurons, although a few originate from intraspinal cells. After complete spinal cord transection, all serotonin from brainstem axons is eliminated caudal to the transection site (Newton and Hamill, 1988, 1989). The specific location of serotonergic fibers in the distal spinal cord of EG-transplanted animals suggests that they have a supraspinal rather than a local origin. The number of intrinsic serotonergic neurons contained in the regions we analyzed (T10-L3) is very low (one or three neurons), and serotonin-immunoreactive fibers were observed in 
EG-containing cords at levels where serotonergic neurons are practically absent (L2-L3) (Newton and Hamill, 1988). Moreover, serotonin-immunopositive neuronal somata were not found in any of the distal spinal cord sections examined, indicating that serotonergic axons detected distally were not sprouts from intraspinal neurons. Previous studies reported the presence of serotonergic fibers in lamina $\mathrm{X}$ of the gray matter of transected spinal cords but not at other cord regions (Newton and Hamill, 1988, 1989). We detected serotonin-immunoreactive axons in the white matter of the ventral columns of EG-transplanted rats, strongly suggesting that those fibers were regenerating from supraspinal neurons instead of local cells. We also detected small dots of serotonin immunoreactivity delineating the cell bodies of motor neurons, indicating that, most likely, some regenerating serotonergic fibers reached their target neurons. In addition, none of the animals from our control group (with SC grafts alone) presented serotonergic fibers in the ventral columns or near motor neurons. Therefore, we conclude that EG transplants made possible the regeneration of axons from brainstem neurons in the injured spinal cord. These regenerating fibers extended beyond the gliotic tissue into the distal cord tissue, reaching the longest distance analyzed $(1.5 \mathrm{~cm})$.

\section{EG transplants promote long-distance axonal regeneration of injured ascending propriospinal axons}

Axonal outgrowth from the grafts into the rostral stump of transected spinal cords in EG-transplanted rats was also indicated by the presence of TMB-stained neuronal somata beyond the distal cord-cable interface. These neurons could only have been labeled if they had picked up the tracer at the injection site (C7), transported it retrogradely, and accumulated it in their somata. This means that regenerating axons from injured propriospinal neurons were able to cross both cord-graft interfaces and elongate through the rostral spinal cord to at least C7. Because grafts were placed between T8 and T10, axons had grown at least $2.5 \mathrm{~cm}$ (between T8 and C7) to reach the tracer injection site. The location of TMB-labeled neuronal bodies within laminae $\mathrm{V}$ and VII of the lower thoracic (T10-T12) and upper lumbar (L1-L3) spinal cord gray matter may suggest that EG induce the regeneration of spinocerebellar, spinoreticular, spinocervical, or spinoannular axons (Tracey, 1985). No labeled somata were observed distal to the graft in control animals.

\section{EG transplants promote growth from the SC graft into the distal spinal cord}

Numerous TMB-labeled fibers were detected in the SC cables and beyond the distal cord-cable interface in EG-containing spinal cords. Some of these traced fibers may be retrogradely filled axons from DRG or spinal neurons that regenerated proximally to the tracer injection site. However, the number of TMBlabeled somata from spinal neurons is small (see above), and axons of these neurons would not account for the large numbers of fibers observed. Moreover, CGRP-positive ascending axons from DRG neurons crossed the distal interface from the dorsal columns (white matter), and TMB-labeled fibers were not observed in the distal cord white matter. Therefore, many of the TMB-labeled fibers observed in the gray matter beyond the distal cord-graft interface may be anterogradely traced descending axons regenerating distally (e.g., propriospinal, brainstem-spinal, corticospinal). In control rats, no labeled axons were detected beyond the distal cord-SC cable interface, although they were seen inside the cable as reported previously (Xu et al., 1997). This indicated that neither axonal regeneration into the distal stump nor long-distance axonal regeneration in the distoproximal direction occurred in controls.

\section{EG migrate within injured spinal cords and improve the environment for axonal regeneration}

EG migrated both longitudinally and laterally from the injection sites in the spinal cord stumps. In both rostral and caudal directions, they reached the farthest distance analyzed $(1.5 \mathrm{~cm})$ and entered SC cables or connective tissue bridges. As reported previously (Ramón-Cueto and Nieto-Sampedro, 1994), migration of EG was not impeded by formed glial scars, and furthermore, EG and reactive glial cells were intermingled. EG moved through either gray or white matter. Therefore, inhibitory molecules from either gliotic tissue (Fernaud-Espinosa et al., 1993) or from myelin (Caroni and Schwab, 1988; Schwab et al., 1993) did not hinder the migration of EG within the CNS. EG were not restricted to the CNS; some cells entered the PNS environment of the dorsal and ventral roots close to the transection site. Axons entering and exiting the CNS through these nearby roots were also transected in their path inside the spinal cord. EG migration inside the roots may be induced by factors released by injured root axons in their attempt to regenerate or by the degenerative process occurring after damage.

EG may provide an appropriate environment for regeneration by accompanying growing axons in the CNS (Ramón-Cueto and Nieto-Sampedro, 1994; present results). It is possible that ensheathment of extending axons by EG could prevent exposure of the axons to inhibitory molecules (Ramón y Cajal, 1928; Reier et al., 1983; Liuzzi and Lasek, 1987; Bandtlow et al., 1990; Smith et al., 1990; Hatten et al., 1991; Bovolenta et al., 1992; FernaudEspinosa et al., 1993; Giulian, 1993; Schwab et al., 1993). EG transplants did not prevent glial scar formation. But interactions between EG and reactive astrocytes or inflammatory cells might change the factors produced by either cell type, thereby modifying the molecular composition of the scar from inhibitory to more permissive to axonal elongation. EG promotion of axonal regeneration could be related to molecules they produce (RamónCueto and Valverde, 1995; Ramón-Cueto and Avila, 1998). EG generate adhesion molecules such as polysialic acid and neural CAMs, laminin, and L1 (Liesi, 1985; Miragall et al., 1988; Ramón-Cueto and Nieto-Sampedro, 1992; Franceschini and Barnett, 1996), which are known promoters of axonal growth, and secrete a variety of growth factors (Ramón-Cueto and Avila, 1998). These cells appear to produce platelet-derived growth factor (Kott et al., 1994), neuropeptide Y (Ubink et al., 1994), glia-derived nexin (Reinhard et al., 1988), S100 (Cummings and Brunjes, 1995; Franceschini and Barnett, 1996), and NGF (Ramón-Cueto et al., 1993; Ramón-Cueto and Avila, 1998). Brainstem serotonergic neurons are responsive to BDNF and neurotrophin-3 (NT-3) in vivo (Xu et al., 1995b; Eaton and Whittemore, 1996; Menei et al., 1998). Because EG transplants elicited long-distance regeneration of serotonergic axons in the transected spinal cord, these cells may also be producing BDNF and NT-3 (Ramón-Cueto and Avila, 1998).

Here, we report that the appropriate conditions for the elongation of serotonergic fibers were provided by EG and fibroblasts of the connective tissue bridges and also by EG in the injured cord tissue. Reactive astrocytes are a source of fibroblast growth factors (FGFs) (Baird and Klagsbrun, 1991; Unsicker et al., 1992; Mocchetti et al., 1996), which support survival and axonal regeneration of injured PNS (Vergara et al., 1993) and CNS (Cheng et 
al., 1996; Mochetti et al., 1996; Nakahara et al., 1996) neurons and enhance the synthesis and secretion of neurotrophins by astrocytes (Onno et al., 1991; Petroski et al., 1991). Accordingly, reactive astrocytes might produce FGFs that, in turn, increase the secretion of trophic or tropic molecules by EG. Although SCs also secrete a large variety of neurotrophic factors (Raivich and Kreutzberg, 1993), they were not sufficient to promote the elongation of serotonergic axons in the presence of either fibroblasts or gliotic tissue (Xu et al., 1997). EG may produce higher amounts of neurotrophins or as yet unidentified factors that may account for the difference in the regenerative abilities of SCs and EG. Also, it should be noted that a barrier to axonal growth forms between the peripheral nerve/SC and CNS tissue environments; this is not known to occur between EG and CNS tissue.

In summary, we found that EG transplants promoted longdistance regeneration of ascending and descending axons in the transected adult mammalian spinal cord. After EG transplantation, damaged axons were able to cross glial scars, enter both spinal cord stumps, and grow through an otherwise nonpermissive CNS environment. Axonal elongation within both rostral and caudal cord stumps was achieved for the longest distance analyzed (2.5 and $1.5 \mathrm{~cm}$, respectively). Moreover, EG migrated from the injection sites toward more rostral and caudal locations, also overcoming the inhibitory nature of CNS tissue. Our present results imply that EG transplants provided injured axons with the conditions needed for their regeneration within the CNS. EG transplants might be used in the future as a tool to foster the regeneration of axons in the lesioned adult mammalian CNS. Alternatively, determination of the factors responsible for the growth-promoting properties of EG might provide useful clues to develop new strategies for treating CNS trauma.

\section{REFERENCES}

Baird A, Klagsbrun M (1991) The fibroblast growth factor family. Ann NY Acad Sci 638:239-243.

Bandtlow C, Zachleder T, Schwab ME (1990) Oligodendrocytes arrest neurite growth by contact inhibition. J Neurosci 10:3837-3848.

Baron-Van Evercooren A, Gansmuller A, Clerin E, Gumpel M (1991) Hoechst 33342 a suitable fluorescent marker for Schwann cells after transplantation in the mouse spinal cord. Neurosci Lett 131:241-244.

Bixby JL, Lilien J, Reichardt LF (1988) Identification of the major proteins that promote neuronal process outgrowth on Schwann cells in vitro. J Cell Biol 107:353-361.

Bovolenta P, Wandosell F, Nieto-Sampedro M (1992) CNS glial scar tissue: a source of molecules which inhibit central neurite outgrowth. Prog Brain Res 94:367-379.

Bregman BS, Kunkel-Bagden E, Schnell L, Dai HN, Gao D, Schwab M E (1995) Recovery from spinal cord injury mediated by antibodies to neurite growth inhibitors. Nature 378:498-501.

Caroni P, Schwab ME (1988) Two membrane protein fractions from rat central myelin with inhibitory properties for neurite growth and fibroblast spreading. J Cell Biol 106:1281-1288.

Chen A, Xu XM, Kleitman N, Bunge M (1996) Methylprednisolone administration improves axonal regeneration into Schwann cell grafts in transected adult rat thoracic spinal cord. Exp Neurol 138:261-276.

Cheng H, Cao Y, Olson L (1996) Spinal cord repair in adult paraplegic rats: partial restoration of hind limb function. Science 273:510-513.

Crowe MJ, Bresnahan JC, Shuman SL, Masters JN, Beattie MS (1997) Apoptosis and delayed degeneration after spinal cord injury in rats and monkeys. Nat Med 3:73-76.

Cummings DM, Brunjes PC (1995) Migrating luteinizing hormonereleasing hormone (LHRH) neurons and processes are associated with a substrate that expresses S100. Dev Brain Res 88:148-157.

David S, Aguayo AJ (1981) Axonal elongation into peripheral nervous system bridges after central nervous system injury in adult rats. Science 214:931-933.
Doucette JR, Kiernan JA, Flumerfelt BA (1983) The re-innervation of olfactory glomeruli following transection of primary olfactory axons in the central or peripheral nervous system. J Anat 137:1-19.

Doucette R (1991) PNS-CNS transitional zone of the first cranial nerve. J Comp Neurol 312:451-466.

Eaton MJ, Whittemore SR (1996) Autocrine BDNF secretion enhances the survival and serotonergic differentiation of raphe neuronal precursor cells grafted into the adult rat CNS. Exp Neurol 140:105-114.

Fawcett JW, Keynes RJ (1990) Peripheral nerve regeneration. Annu Rev Neurosci 13:43-60.

Fernaud-Espinosa I, Nieto-Sampedro M, Bovolenta P (1993) Differential activation of microglia and astrocytes in aniso- and isomorphic gliotic tissue. Glia 8:277-291.

Franceschini IA, Barnett SC (1996) Low-affinity NGF-receptor and E-N-CAM expression define two types of olfactory nerve ensheathing cells that share a common lineage. Dev Biol 173:327-343.

Gibson S, Polak JM, Bloom SR, Sabate IM, Mulderry PM, Ghatei MA, McGregor GP, Morrison JFB, Kelly JS, Evans RM, Rosenfeld MG (1984) Calcitonin gene-related peptide immunoreactivity in the spinal cord of man and of eight other species. J Neurosci 4:3101-3111.

Giulian D (1993) Reactive glia as rivals in regulating neuronal survival. Glia $7: 102-110$.

Graziadei P, Monti Graziadei G (1980) Neurogenesis and neuron regeneration in the olfactory system of mammals. III. Deafferentation and reinnervation of the olfactory bulb following section of the fila olfactoria in rat. J Neurocytol 9:145-162.

Guénard VN, Xu XM, Bunge MB (1993) The use of Schwann cell transplantation to foster central nervous system repair. Semin Neurosci 5:401-411.

Guest JD, Rao A, Olson L, Bunge MB, Bunge RP (1997) The ability of human Schwann cell grafts to promote regeneration in the transected nude rat spinal cord. Exp Neurol 148:502-522.

Hagg T, Vahlsing HL, Manthorpe M, Varon S (1990) Septohippocampal cholinergic axonal regeneration through peripheral nerve bridges: quantification and temporal development. Exp Neurol 109:153-163.

Harvey AR, Chen M, Plant GW, Dyson SE (1994) Regrowth of axons within Schwann cell-filled polycarbonate tubes implanted into the damaged optic tract and cerebral cortex of rats. Rest Neurol Neurosci 6:221-237.

Hatten ME, Liem RKH, Shelanski ML, Mason C (1991) Astroglia in CNS injury. Glia 4:233-243.

Kalderon N, Fuks Z (1996) Severed corticospinal axons recover electrophysiologic control of muscle activity after x-ray therapy in lesioned adult spinal cord. Proc Natl Acad Sci USA 93:11185-11190.

Kott JN, Westrum LE, Raines EW, Sasahara M, Ross R (1994) Olfactory ensheathing glia and platelet-derived growth factor B-chain reactivity in the transplanted rat olfactory bulb. Int $\mathrm{J}$ Dev Neurosci 12:315-323.

Kromer LF, Cornbrooks CJ (1985) Transplants of Schwann cell cultures promote axonal regeneration in the adult mammalian brain. Proc Natl Acad Sci USA 82:6330-6334.

Li Y, Field PM, Raisman G (1997) Repair of adult rat corticospinal tract by transplants of olfactory ensheathing cells. Science 277:2000-2002.

Liesi P (1985) Laminin immunoreactive glia distinguish regenerative adult CNS systems from non-regenerative ones. EMBO J 4:2505-2511.

Liuzzi FJ, Lasek RJ (1987) Astrocytes block axonal regeneration in mammals by activating the physiological stop pathway. Science 237:642-645.

Menei P, Montero-Menei C, Whittemore SR, Bunge RP, Bunge MB (1998) Schwann cells genetically modified to secrete human BDNF promote enhanced axonal regrowth across transected adult rat spinal cord. Eur J Neurosci 10:607-621.

Mesulam MM (1978) Tetramethyl benzidine for horseradish peroxidase neurohistochemistry: a non-carcinogenic blue reaction product with superior sensitivity for visualizing neural afferents and efferents. J Histochem Cytochem 26:106-117.

Miragall F, Kadmon G, Husmann M, Schachner M (1988) Expression of cell adhesion molecules in the olfactory system of the adult mouse: presence of the embryonic form of N-CAM. Dev Biol 129:516-531.

Mocchetti I, Rabin SJ, Colangelo AM, Whittemore SR, Wrathall JR (1996) Increased basic fibroblast growth factor expression following contusive spinal cord injury. Exp Neurol 141:154-164.

Montgomery CT, Robson JA (1993) Implants of cultured Schwann cells support axonal growth in the central nervous system of adult rats. Exp Neurol 122:107-124. 
Morrissey TK, Kleitman N, Bunge RP (1991) Isolation and functional characterization of Schwann cells isolated from adult peripheral nerves. J Neurosci 11:2433-2442.

Nakahara Y, Gage FH, Tuszynski MH (1996) Grafts of fibroblasts genetically modified to secrete NGF, BDNF, NT-3, or basic FGF elicit differential responses in the adult spinal cord. Cell Transplant 5:191-204.

Newton BW, Hamill RW (1988) The morphology and distribution of rat serotoninergic intraspinal neurons: an immunohistochemical study. Brain Res Bull 20:349-360.

Newton BW, Hamill RW (1989) Immunohistochemical distribution of serotonin in spinal autonomic nuclei. I. Fiber patterns in the adult rat. J Comp Neurol 279:68-81.

Onno T, Saito H, Kishimoto T, Okumoto T, Miyamoto K (1991) Stimulation of biosynthesis of nerve growth factor by acidic fibroblast growth factor in cultured mouse astrocytes. Neurosci Lett 126:18-20.

Oudega M, Hagg T (1996) Nerve growth factor promotes regeneration of sensory axons into adult rat spinal cord. Exp Neurol 140:218-229.

Petroski RE, Grierson JP, Choi-Kwon S, Geller HM (1991) Basic fibroblast growth factor regulates the ability of astrocytes to support hypothalamic neuronal survival. Dev Biol 147:1-13.

Raivich G, Kreutzberg GW (1993) Peripheral nerve regeneration: role of growth factors and their receptors. Int J Dev Neurosci 11:311-324.

Ramón-Cueto A, Avila J (1998) Olfactory ensheathing glia: properties and function. Brain Res Bull, in press.

Ramón-Cueto A, Nieto-Sampedro M (1992) Glial cells from adult rat olfactory bulb: immunocytochemical properties of pure cultures of ensheathing cells. Neuroscience 47:213-220.

Ramón-Cueto A, Nieto-Sampedro M (1994) Regeneration into the spinal cord of transected dorsal root axons is promoted by ensheathing glia transplants. Exp Neurol 127:232-244.

Ramón-Cueto A, Valverde F (1995) Olfactory bulb ensheathing glia: a unique cell type with axonal growth-promoting properties. Glia 14:163-173.

Ramón-Cueto A, Pérez J, Nieto-Sampedro M (1993) In vitro enfolding of olfactory neurites by 75 NGF receptor positive ensheathing cells from adult rat olfactory bulb. Eur J Neurosci 5:1172-1180.

Ramón y Cajal S (1928) Degeneration and regeneration of the nervous system (May RM, translator). New York: Oxford UP.

Reier PJ, Stensaas LJ, Guth L (1983) The astrocytic scar as an impediment to regeneration in the central nervous system. In: Spinal cord reconstruction (Cao CC, Bunge RP, Reier PJ, eds), pp 163-198. New York: Raven.

Reinhard E, Meier R, Halfter W, Rovelli G, Monrad D (1988) Detection of glia-derived nexin in the olfactory system of the rat. Neuron 1:387-394.
Sauve Y, Sawai H, Rasminsky M (1995) Functional synaptic connections made by regenerated retinal ganglion cell axons in the superior colliculus of adult hamsters. J Neurosci 15:665-675.

Schnell L, Schneider R, Kolbeck R, Barde YA, Schwab ME (1994) Neurotrophin-3 enhances sprouting of corticospinal tract during development and after adult spinal cord lesion. Nature 367:170-173.

Schwab ME, Kapfhammer JP, Bandtlow CE (1993) Inhibitors of neurite growth. Annu Rev Neurosci 16:565-595.

Smith GM, Rutishauser U, Silver J, Miller RH (1990) Maturation of astrocytes in vitro alters the extent and molecular basis of neurite outgrowth. Dev Biol 138:377-390.

Son YJ, Trachtenberg JT, Thompson WJ (1996) Schwann cells induce and guide sprouting and reinnervation of neuromuscular junctions. Trends Neurosci 19:280-284.

Tracey DJ (1985) Ascending and descending pathways in the spinal cord. In: The rat nervous system: hindbrain and spinal cord, Vol 2 (Paxinos G, ed), pp 311-324. Sydney: Australia: Academic.

Tuszynski MH, Peterson DA, Ray J, Baird A, Nakahara Y, Gage FH (1994) Fibroblasts genetically modified to produce nerve growth factor induce robust neuritic ingrowth after grafting to the spinal cord. Exp Neurol 126:1-14.

Ubink R, Halasz N, Zhang X, Dagerlind A, Hokfelt T (1994) Neuropeptide tyrosine is expressed in ensheathing cells around the olfactory nerves in the rat olfactory bulb. Neuroscience 60:709-726.

Unsicker K, Grothe C, Westermann R, Wewetzer K (1992) Cytokines in neural regeneration. Curr Opin Neurobiol 2:671-678.

Vergara J, Medina L, Maulen J, Inestrosa NC, Alvarez J (1993) Nerve regeneration is improved by insulin-like growth factor I (IGF-I) and basic fibroblast growth factor (bFGF). Rest Neurol Neurosci 5:181-189.

Xu XM, Guénard V, Kleitman N, Bunge MB (1995a) Axonal regeneration into Schwann cell-seeded guidance channels grafted into transected adult rat spinal cord. J Comp Neurol 351:145-160.

Xu XM, Guénard V, Kleitman N, Aebischer P, Bunge MB (1995b) A combination of BDNF and NT-3 promotes supraspinal axonal regeneration into Schwann cell grafts in adult rat thoracic spinal cord. Exp Neurol 134:261-272.

Xu XM, Chen A, Guénard V, Kleitman N, Bunge MB (1997) Bridging Schwann cell transplants promote axonal regeneration from both the rostral and caudal stumps of transected adult rat spinal cord. J Neurocytol 26:1-16.

Ye JH, Houle JD (1997) Treatment of the chronically injured spinal cord with neurotrophic factors can promote axonal regeneration from supraspinal neurons. Exp Neurol 143:70-81. 